\title{
Effects and treatment of malabsorption in childhood
}

\author{
By June K. Lloyd, Department of Child Health, Institute of Child Health, University \\ of London, 30 Guilford Street, London WCI $N_{\mathrm{I}} E H$
}

The effects and treatment of malabsorption in childhood will obviously vary according to the nature and severity of the underlying cause, and the age of the child. This paper describes briefly the general nutritional effects with particular reference to coeliac disease, which is one of the most common causes of malabsorption in Western countries (Anderson, I966), and discusses some of the types of treatment, both specific and non-specific, used in various malabsorptive states.

\section{Effects}

Growth retardation. This is the most frequent consequence of malabsorption, irrespective of cause; in general, weight is usually more severely affected than height, although this varies with the age of presentation. In children with coeliac disease, growth failure is more prominent in older children (Hamilton, Lynch \& Reilly, I969; Young and Pringle, I97I; Rey, Rey, Jos \& Lora, I97 I); thus in 110 children studied by Young \& Pringle (1971) $60 \%$ of the 36 children who presented over the age of 4 years showed extreme stunting of growth with heights below the third percentile for age, whereas only $28 \%$ of children under the age of 4 years had heights on or below the third percentile. Younger children, however, are more likely to have lost weight; two-thirds of the children under 4 years were below the third percentile in weight compared with slightly over one-third in the older group reported by Young \& Pringle (1971); similar observations were made by Hamilton et al. (1969) and Rey et al. (197 I). Muscle wasting, particularly of the proximal muscles, is common, and this feature together with abdominal protruberance was emphasized by Gee ( 1888 ) in his classical description of the 'coeliac affection'.

The effects of malabsorption of specific nutrients. These are often overshadowed in children by the more obvious effects on growth. Nevertheless, oedema due to hypoproteinaemia, anaemia due to deficiency of iron or folate or both, and rickets or osteomalacia, due to malabsorption of calcium and vitamin D, can occur and may occasionally be the presenting feature. Impaired digestion of protein is the primary abnormality in the newly recognized disorder of enterokinase deficiency (Tarlow, Hadorn, Arthurton \& Lloyd, 1970) and in this condition hypoproteinaemic oedema is an early manifestation. Hypoproteinaemia, usually confined to a reduction in serum albumin concentration, may occur in coeliac disease due to malabsorption of protein or excessive intestinal protein loss or both. Serum total protein was below normal in just over half of the younger children in the study by Young \& Pringle (197I) 
and hypoalbuminaemia was recorded in a third of the patients reported by Hamilton et al. (1969). These latter patients all had oedema and, in addition, two other children without hypoalbuminaemia presented with oedematous legs, possibly due to venous or lymphatic obstruction.

Anaemia is common in coeliac disease, and was present in about $80 \%$ of children in the series of both Hamilton et al. (1969) and of Young \& Pringle (1971). Serum iron concentration and serum (or whole blood) folate are frequently low, but the anaemia is usually hypochromic and microcytic; a megaloblastic peripheral blood smear is unusual. Occasionally, anaemia is the presenting feature in an older child who appears otherwise well and has no intestinal symptoms or evidence of growth retardation. Malabsorption of vitamin $\mathrm{K}$ may result in prolongation of the prothrombin time but haemorrhagic manifestations are rare.

Radiology of the bones shows retardation of skeletal age commensurate with height retardation. In coeliac disease, although absorption of calcium and vitamin D are likely to be impaired, rickets is uncommon; osteoporosis, however, occurs in children as in adults and was found in $50 \%$ of the children examined by IIamilton et al. ( 1969 ). These authors also found serum calcium concentration to be low in fifteen of forty-one children, although nine of those with hypocalcaemia also had hypoalbuminaemia. Other features in coeliac disease which may be of nutritional origin include a smooth tongue, finger clubbing and unusually long eyelashes (Hamilton et al. 1969 ).

Malabsorptive states leading to malnutrition in the early months of life may have effects on both growth and maturation of the brain. Discussion of this important aspect is outside the scope of this paper, but it serves to emphasize the need for early diagnosis and treatment of malabsorption in infants and young children.

\section{Treatment}

Where the cause of malabsorption is known, specific treatment which will restore normal physiological functioning may be available. In some instances, however, although the underlying defect is known, correction of this is not yet possible and therapy in such cases is symptomatic. Symptomatic and supportive treatment is also required for those children in whom the basic abnormality is not clearly understood and some of whom may recover spontaneously if nutrition can be maintained during the acute stage of their illness.

Specific treatment. Specific treatment may take the form of drug therapy to eradicate infection, for example in giardia lamblia infection; or restoration of defective enzymic digestion may be possible by oral replacement therapy, as in the treatment of enterokinase deficiency with pancreatic extract (Tarlow et al. 1970); or elimination of a 'toxic' dietary constituent may be required as in the treatment of coeliac disease with a gluten-free diet.

The treatment of coeliac discase in childhood provides a demonstration of the remarkable degree to which children can regain a normal nutritional state and growth pattern, and also illustrates the nced for the symptomatic and temporary treatment of secondary deficiency states. In addition to the exclusion of gluten from the diet, 
secondary disaccharide intolerance may necessitate the withdrawal of lactose and sucrose (Arthur, Clayton, Cottom, Seakins \& Platt, 1966) during the early stages of therapy. The number of children requiring this added measure is, however, probably small (McNeish \& Sweet, I968; Young \& Pringle, I97I) and the disaccharides can, anyway, usually be reintroduced after $3-6$ months. A few children who present with severe diarrhoea and marked steatorrhoea may require fluid restoration by intravenous infusion, and may respond symptomatically to reduction in the amount of dietary fat. All children probably need supplementary iron and folic acid at some stage to replete body stores, and adequate intake of fat soluble vitamins must be ensured.

With adequate treatment most children with coeliac disease may be expected to show satisfactory 'catch-up' growth. In a study of twenty-nine children in whom the diagnosis was established between the ages of 6 months and 2 years, Prader, Shmerling, Zachman \& Biro (1969) showed that full 'catch-up' in weight had been achieved 6 months to I year after treatment, height 'catch-up' was reached in I-2 years and skeletal maturation was normal by $2-3$ years. The range of cereals that require exclusion from the diet and the duration of dietary treatment are still matters for some debate. There is general agreement that wheat and rye must be completely excluded, and that buckwheat and millet are harmless (Weijers, Lindquist, Anderson Rey, Shmerling, Visakorpi, Hadorn \& Grüttner, I970); the situation regarding oats and barley is less clear and further studies are needed of the effects of these cereals. With regard to the duration of gluten exclusion, most paediatricians now acknowledge that the diet must be maintained throughout childhood and until growth is complete, and many paediatricians would agrce with the conclusions of Sheldon (1969) that a gluten-free diet should be maintained for life in view of the high relapse-rate in young adults who have had coeliac disease in childhood. It is therefore important that the diagnosis of permanent gluten intolerance is firmly established in individual patients, and this will necessitate confirmation of the initial diagnosis by intestinal biopsy and may require subsequent biopsies under different dietary regimens.

Sympotomatic and supportive treatment. Examples of conditions in which the basic defect responsible for malabsorption is known but cannot be corrected include abetalipoproteinaemia, in which fat malabsorption is due to failure of chylomicron formation; glucose-galactose malabsorption, in which there is a specific transport defect for these monosaccharides; and extensive intestinal resection (usually performed in the newborn period on account of congenital malformations), in which absorption of many nutrients may be impaired. Severe malabsorption may also occasionally occur in infants who have had intestinal surgery without resection and in infants who have had proven or suspected infective diarrhoea. In this latter group, severe malnutrition may be present in the acute stages, but spontaneous recovery can occur. In spite of the lack of specific therapy all these conditions may be expected to respond to symptomatic treatment.

In abetalipoproteinaemia, steatorrhoea can be controlled by reduction in dietary fat intake, and this measure alone may be sufficient to promote 'catch-up' growth 
and thereafter maintain normal growth progress (Lloyd \& Muller, 1972). For those children in whom adequate caloric intake cannot be achieved on a low-fat diet, fat in the form of medium-chain triglycerides, whose fatty acids are not incorporated into chylomicrons but enter the portal vein, may provide a useful adjunct. Supplementary fat-soluble vitamins are also required.

The diarrhoea of glucose-galactose malabsorption promptly ceases when these monosaccharides (and the disaccharides from which they are derived) are withdrawn from the diet and fructose is used as the carbohydrate source. Before the recognition of the basic abnormality in sugar transport it is probable that the majority of affected individuals died in the first few months of life, but with early diagnosis and treatment, normal physical and mental development can be expected (Meeuwisse \& Melin, I969). In childhood and later life, strict adherence to the diet becomes increasingly difficult, starch and sucrose have to be introduced in modest amounts and most individuals accept occasional episodes of abdominal discomfort and diarrhoea.

The management of infants with extensive resection of the small intestine, or with protracted diarrhoea and malnutrition following intestinal infections or surgery without resection, often presents major problems. In the early stages it may prove impossible to maintain either hydration or nutrition by oral feeding, and in such circumstances fluid and nutritional requirements have to be given by the intravenous route. Preparations of amino acids, monosaccharides and fat emulsions are now available in a form suitable for infusion over prolonged periods and, together with electrolytes, trace elements and vitamins, can be used to provide complete intravenous nutrition (Harries, 1971). While such a regimen can be lifesaving, it carries a high risk of complications including septicaemia, metabolic acidosis, venous obstruction and heart failure, and every attempt should be made to re-establish oral feeding as soon as possible. Detailed investigation of the absorptive function of this group of infants is often impracticable, and dietary regimens have to be designed on an empirical basis together with a certain amount of trial and error. Most babies prove to be intolerant of disaccharides, and lactose and sucrose should be excluded; efficiency of absorption of the monosaccharides varies considerably, and in some cases a mixture of glucose and fructose is tolerated in a higher total concentration than would be possible using either sugar alone. Commercial milk preparations containing glucose or fructose as the carbohydrate source are available. If fat malabsorption is severe, and the intake has to be reduced, additional calories may be supplied in the form of medium-chain triglycerides. This fat, which supplies $8.3 \mathrm{kcal}(34.7 \mathrm{~kJ}) / \mathrm{g}$, is more readily absorbed than ordinary dietary fat in most malabsorptive states (Leyland, Fosbrooke, Lloyd, Segall, T'amir, Tomkins \& Wolff, r 969 ) and can be particularly useful for young infants with resection or temporary malabsorption. A filled-milk preparation containing mediumchain trigylcerides as the source of fat, and glucose as the carbohydrate, is commercially available. Occasionally, infants appear to be intolerant of cows' milk protein; human milk is likely to be unsuitable (even if available), because of its lactose content, and other proteins have to be incorporated into the fluid feed. At the 
Hospital for Sick Children, Great Ormond Street, we have found that a feed based on chicken, medium-chain triglycerides and monosaccharide (glucose or fructose or both) can provide satisfactory nutrition for infants with complicated food intolerance (D. E. M. Francis, personal communication). All infants on synthetic diets require supplements of minerals, including trace elements, and vitamins (Harries \& Francis, I968).

Once diarrhoea has ceased and satisfactory growth progress has been firmly established, the range of foods given to these babies can be increased. All introductions are best made singly and slowly, and eventually it should be possible to reintroduce a normal diet. The ultimate progress of children after even massive resection of the small bowel in early infancy can be surprisingly good (Young, Swain \& Pringle, 1969) and every effort should be made to maintain optimum nutrition in the early months of life. Improvements in the techniques of intravenous feeding, the availability of suitable preparations for both intravenous and oral use, and increasing knowledge of the abnormalities of digestion and absorption have all contributed to a significant advance in recent years in the management of infants with this type of malabsorption.

\section{Summary}

The main clinical consequence of malabsorption in childhood is impairment of growth; specific effects such as hypoproteinaemic oedema due to protein malabsorption, anaemia due to defective absorption of iron or folic acid, or rickets due to vitamin $\mathrm{D}$ deficiency, are less common as presenting features. Treatment depends upon the cause; where a specific abnormality can be identified and corrected, such as gluten exclusion in coeliac disease or oral administration of pancreatic extract in enterokinase deficiency, the results are usually excellent. Even when the basic defect cannot be reversed, or is not identified, symptomatic treatment is often successful. Special diets are usually required; monosaccharides may be used to replace disaccharides and medium-chain triglyceride substituted for ordinary dietary fat. Occasionally, oral feeding proves impossible and nutrition can only be maintained by the intravenous route.

\section{REFERENCES}

Anderson, C. M. (1966). Archs Dis. Childh. 4I, 57 I.

Arthur, A. B., Clayton, B. E., Cottom, D. G., Seakins, J. W. T. \& Platt, J. W. (1966). Lancet i, 172. Gee, S. (1888). St Bart's Hosp. Rep. 24, I7.

Hamilton, J. R., Lynch, M. J. \& Reilly, J. B. (1969). Q. $f l$ Med. 38, 135.

Harries, J. T. (1971). Archs Dis. Childh, 46, 855.

Harries, J. T. \& Francis, D. E. M. (1968). Acta paediat. scand. 57, 505.

Leyland, F. C., Fosbrooke, A. S., Lloyd, J. K., Segall, M. M., Tamir, I., 'Tomkins, R. \& Wolff, O. M. (1969). Archs Dis. Childh. 44, 107.

Lloyd, J. K. \& Muller, D. P. R. (1972). In Proceedings of the Twentieth International Colloquium on Protides of the Biological Fluids [H. Peeters, editor]. Oxford: Pergamon Press.

McNeish, A. S. \& Sweet, E. M. (1968). Archs Dis. Childh. 43, 433.

Meeuwisse, G. W. \& Melin, K. (1969). Acta paediat. scand. Suppl. I 88.

Prader, A., Shmerling, D. H., Zachman, M. \& Biro, Z. (1969). Acta paediat. scand. 58, 3 I т.

Rey, J., Rey, F., Jos, J. \& Lora, S. A. (1971). Archs fr. Pédiat. 28, 37. 
Sheldon, W. (1969). Br. med. F. ii, $40 \mathrm{r}$.

Tarlow, M. J., Hadorn, B., Arthurton, M. W. \& Lloyd, J. K. (1970). Archs Dis. Childh. 45, $65 \mathrm{r}$.

Weijers, H. A., Lindquist, B., Anderson, C. M., Rey, J., Shmerling, D. I1., Visakorpi, J. K., Hadorn, B. \& Grüttner, R. (1970). Acta paediat. scand. 59, $46 \mathrm{r}$.

Young, W. F. \& Pringle, E. M. (197I). Archs Dis. Childh. 46, 421.

Young, W. F., Swain, V. A. J. \& Pringle, E. M. (1969). Archs Dis. Childh. 44, 465. 